\title{
A HOMOFOBIA: uma discussão da Homossexualidade, Drogas e a AIDS através do filme Dallas Byers Club
}

DOI: $10.22289 / 2446-922 X . V 4 N 1 A 10$

\author{
Patricia da Cunha Gomes ${ }^{1}$ \\ Gilmar Antoniassi Júnior
}

\section{RESUMO}

O objetivo do estudo é discutir através do filme Dallas Byers Club as implicações do comportamento homofóbico ante a homossexualidade, drogas e a AIDS. Utilizou-se um delineamento qualitativo de estudo de caso de natureza descritiva histórica através do método de história de vida, por meio de análise de filme. O filme é baseado fatos reais, no enredo da história Ron Woodroof (Matthew McConaughey), consumidor de drogas, amante de mulheres, homofóbico, que, em 1986, foi diagnosticado com aids e recebeu a sentença de 30 dias de vida. Pode-se perceber que a homofobia não é um assunto remoto, o preconceito e discriminação vivida por Ron Woodroof nos anos 80 , pode ser visto com tantos outros na atualidade, apesar de muita coisa ter mudado, as pessoas estarem mais instruídas, tomando consciência que a AIDS e o uso de drogas não é exclusividade de homossexuais, que, heterossexuais e afins são tão vulneráveis quanto.

Palavras-chave: Homofobia; Homossexualidade; Drogas; AIDS.

\section{ABSTRACT}

The goal of the study is to discuss through the Dallas Byers Club movie the implications of homophobic behavior toward homosexuality, drugs and AIDS. A qualitative study of a case study of a descriptive historical nature was used through the life history method, through film analysis. The film is based on real facts, in the plot of the story Ron Woodroof (Matthew McConaughey), drug user, female lover, homophobic, who in 1986 was diagnosed with AIDS and received the sentence of 30 days of life. It can be seen that homophobia is not a remote subject, the prejudice and discrimination lived by Ron Woodroof in the 80's, can be seen with many others today, although much has changed, people are more educated, becoming aware that AIDS and drug use is not exclusive to homosexuals, who, heterosexuals and the like are just as vulnerable.

Keywords: Homophobia; Homosexuality; Drugs; AIDS.

\footnotetext{
${ }^{1}$ Endereço eletrônico de contato: patcunhagomes.pcg@gmail.com

Recebido em 18/10/2017. Aprovado pelo conselho editorial para publicação em 20/10/2017.
}

Rev. Psicol Saúde e Debate. Fev., 2018:4(1):161-170. 


\section{INTRODUÇÃO}

O termo homofobia, segundo Junqueira (2007), surgiu durante os anos 70 nos Estados Unidos selado pelo psicólogo clínico George Weinberg, e basicamente consiste na aversão, ódio a pessoas que optam por ter relações homossexuais ou que de qualquer forma tenha uma orientação diferente da que é aceita pelo contexto social.

A exteriorização da homofobia segundo Scola \& Amaral (2007), tem seu fundamento em argumentos religiosos, políticos, culturais e etc. Está intimamente ligado à necessidade que alguns indivíduos têm de reafirmar os papéis tradicionais de seu gênero, ancorada em uma sociedade com dominação masculina e heteronormativa.

Bourdieu (1999), salientada como algo ao mesmo tempo arbitrário e eternizado. A história pessoal está, portanto, articulada à história social. Por sua vez, a repressão e o autoritarismo na infância, na formação e na educação são internalizados de forma profunda e repercutem na vida adulta. Aquela significa que o padrão em uma sociedade é que a pessoa seja heterossexual. Nesse sentido, todas as outras formas de variações de comportamento e orientação sexual seria considerada anormal.

Acolhido atualmente por algumas pessoas com certa repulsa, o fenômeno da homossexualidade em sociedades antigas, era tolerado. Em determinadas comunidades como a grega, consoante o atestado por Silva \& Bornia (2009), as relações homossexuais eram vistas em uma posição hierarquicamente superior às relações heterossexuais, tendo inclusive uma função civil, pois eram a partir delas que o jovem grego passava a ser visto como cidadão.

Conjuntamente, durante o Império Romano a questão da homossexualidade sofreu modificações. Para Moreira \& Madrid (2008), no início do Império romano o homossexualismo entre romanos e jovens eram eminentemente aceitos, porém, com o passar do tempo foi sofrendo restrições, podendo, a depender de quem estivesse envolvido na relação ser sujeito a multa. Salienta-se, que o fenômeno do homossexualismo não está limitado às sociedades ocidentais, já que em civilizações orientais como, por exemplo, a chinesa e a Indiana, seja por motivo religioso ou cultural, o homossexualismo era visto com naturalidade.

Durante a Idade Média, de acordo com Silva \& Bornia (2009), a relação homossexual devido à influência de fatores religiosos passou a ser bastante oprimida, tendo sido o prazer sexual de um modo geral visto como pecado, uma tentação diabólica. Ainda na mesma vertente, outro período de numerosas comprovações dos traços homofóbicos foi durante a Segunda Guerra Mundial, onde homossexuais juntamente com ciganos, judeus negros e outros, foram vítimas de graves violências, em nome da "superioridade da raça ariana". Pós- 
guerra, segundo Toniette (2006), o Movimento dos Direitos dos Homossexuais começou a se estruturar nos Estados Unidos da América e na Europa, onde a principal proposta desse movimento era descriminalizar a homossexualidade e ter o reconhecimento dos seus direitos civis.

Após séculos de repressão, a homossexualidade conceituada como pecado e/ou doença, no início dos anos 70 encetou esse modo de pensar, segundo Junqueira (2007), em 1973 a Associação Americana de Psiquiatria retirou a homossexualidade do Manual de Diagnóstico de Distúrbios Mentais (DSM) como doença, e em 1990 a Organização Mundial de Saúde (OMS) excluiu do Código Mundial de Doenças. No Brasil, desde 1985 os Conselhos Federais de Medicina, e desde 1999 os Conselhos de Psicologia não a consideram como doença, distúrbio mental ou perversão.

Todo esse sentimento que é capaz de gerar atos discriminatórios com alto nível de hostilidade, chegando a ponto de condutas agressivas, carregadas de constrangimentos, prejuízos e profunda dor emocional na vida dos indivíduos homossexuais de qualquer espécie (Oliveira, 2009). As práticas homofóbicas não tem lugar nem espaço definido, ocorrem em todas as áreas do convívio social, seja nas escolas, atingindo diretamente as crianças com trejeitos gays por exclusão ou isolamento, ou ainda adultos e jovens nas universidades ou até mesmo nos locais de trabalho.

Note-se que o preconceito está disseminado em toda sociedade brasileira, seja esta moral ou imoral, ultrapassando os limites da esfera religiosa ou o conservadorismo dos indivíduos de idade elevada na sociedade. Os agressores não possuem perfil especifico, são encontrados em diversos ambientes e costumes, e as condutas discriminatórias variam de acordo com as características individuais de cada um. Pode-se afirmar que a violência vai de encontro com à integridade moral, psicológica física ou sexual, sendo que diante de qualquer sentimento que impeça a experimentação de algo, de forma infundada representa um tipo de violência (Oliveira, 2009).

A propósito, os não simpatizantes, os que tomam papéis de guardiões da família, da palavra de Deus, emanam comportamentos não apenas sádicos, mas preconceituosos, ditatoriais, e até mesmo ignorantes, além de não possuírem legitimidade ao negar os direitos mais elementares, vez que conforme previsto constitucionalmente, todos sem exceção têm direito à liberdade de expressão, opinião e orientação sexual, ademais, a homossexualidade é um fenômeno natural tanto quanto a heterossexualidade.

Por preconceito, designam-se as percepções mentais negativas em face de indivíduos e de grupos socialmente inferiorizados, bem como as representações sociais conectadas a tais percepções. Já o termo discriminação aponta a projeção, concretizada nas 
relações sociais, de condutas aleatórias, comissivas ou omissivas, concernente ao prejulgamento, que violam os direitos individuais e/ou grupais (Rios, 2009).

Deste modo, a homofobia no Brasil como nos demais países ganham destaque nos noticiários, pelos excessivos e constantes ataques violentos aos quais as pessoas homossexuais têm sofrido. Devido a situação de vulnerabilidade exposta, a saúde destes sujeitos é afetada de forma constante, que provoca alterações comportamentais caracterizando sofrimento interposto na adoção de hábitos de vida não saudáveis, como o abuso das drogas para aliviar a sofrença. Nesta perspectiva, o presente trabalho tem como objetivo discutir através do filme Dallas Byers Club as implicações do comportamento homofóbico ante a homossexualidade, drogas e a AIDS.

\section{MÉTODO}

Utilizou-se um delineamento qualitativo de estudo de caso de natureza descritiva histórica através do método de história de vida, mediante a história narrada no filme 'Dallas Byers Club'.

Trata-se de uma história de Ron Woodroof (Matthew McConaughey), consumidor de drogas, amante de mulheres, homofóbico, que, em 1986, foi diagnosticado com AIDS e recebeu a sentença de 30 dias de vida. A partir daí sua luta pela vida intensificou-se e, quase à beira da morte, ele foi em busca de medicamentos alternativos fora do país já que o único remédio legal nos Estados Unidos para combater a doença, na época, era o AZT. Com a ajuda de sua médica, dra. Eve Saks (Jennifer Garner), e do travesti Rayon (Jared Leto), portador do HIV, Woodroof criou clubes em que as pessoas pagavam por esses tratamentos alternativos, o que levou as indústrias farmacêuticas dos Estados Unidos a travarem uma guerra contra ele. Woodroof morreu em 12 de setembro de 1992, seis anos após o diagnóstico fatal (Brenner et al. \& Vallée, 2013).

A escolha do filme deu-se por abordar no enredo da história ter sido uma inspiração de história de vida real, e na temática conter a narrativa em relação a homofobia homossexualidade - drogas - AIDS. Articulando com o referencial teórico no campo da Psicologia da Saúde e Saúde Coletiva, para promover a discussão. 


\section{RESULTADO E DISCUSSÃO}

Os fatos se baseiam em Ron Woodroof, um caipira homofóbico de Dallas que acidentalmente descobre ter AIDS - síndrome da imunodeficiência adquirida (acquired immunodeficiency syndrome) - após um exame de sangue que visava descobrir o motivo de um desmaio.

Logo após o diagnóstico, o médico se diz espantado pelo fato de Ron ainda estar vivo, tendo em vista sua situação vulnerável, e lhe dá cerca de 30 dias de vida. Ron reluta em acreditar, pois naquela época, a incidência de AIDS era muito frequente em usuários de drogas injetáveis, pessoas que faziam sexo sem proteção - onde o mesmo se encaixava- e homossexuais. Guiado pelo seu machismo exacerbado, não consegue crer em sua situação, no entanto, os sintomas começam a aparecer rapidamente e leva preocupação a Ron, que, a partir daí, resolve pesquisar um tratamento para si.

É válido salientar que, as relações entre homossexualidade e saúde neste último século têm sido motivo de debates e controvérsias, tanto no âmbito das ciências médicas como no dos movimentos sociais. Durante este período, a homossexualidade foi considerada uma doença, e os indivíduos com práticas homossexuais, tratados como se fossem portadores de alguma patologia ou distúrbio, que poderia ser diagnosticado como de origem biológica, genética ou de um desenvolvimento psíquico inadequado (Cancian, 2017; Daniel \& Parker, 1991).

O advento da AIDS, no início dos anos 80, laborioso estas relações e serviu de motivo para o recrudescimento de preconceitos contra os homossexuais, e a própria homossexualidade masculina se transformou num sinônimo de AIDS. No início, a associação chegou a tal ponto que a doença, recém-descoberta, chegou a ser chamada de GRID (Gay Related Immunedeficiency) nos meios científicos e de câncer gay, peste gay ou peste rosa pela imprensa e pela opinião pública (Daniel \& Parker, 1991).

De acordo com notícia da revista Exame (2011), a AIDS continua um grave problema no cotidiano dos homossexuais masculinos. As representações sociais que identificavam os homossexuais ora como vilões, ora como vítimas da AIDS, ainda permanecem e fazem com que, individualmente, continuem a sofrer com os estigmas e preconceitos decorrentes da associação AIDS-homossexualidade e pela possibilidade de vir a infectar-se com o HIV, caso não sejam adotadas práticas sexuais seguras. Coletivamente, a epidemia ainda se impõe como um problema que exige respostas de diferentes setores governamentais e demanda mobilização para que recursos sejam garantidos e aplicados na prevenção e assistência, para 
que a discriminação e o preconceito sejam denunciados e punidos, para que os direitos humanos sejam respeitados.

As complexas relações entre homossexualidade e as políticas de saúde podem ser ilustradas pelo seguinte exemplo: no Brasil, os homossexuais (que se auto-identificam na hora da doação) são proibidos de doar sangue nos bancos de sangue por portaria do Ministério da Saúde, que os considera um potencial grupo de risco para a AIDS e outras doenças transmissíveis por via sanguínea. Tal decisão vem sendo questionada pelo movimento homossexual e pelas ONGs/AIDS pelo seu caráter discriminador e estigmatizante, que pode estar trazendo mais danos à população do que efetivamente contribuindo para um controle da epidemia e de outras doenças (Grodira, 2014).

Dando sequência, Ron soube que um grupo de pessoas usariam AZT (zidovudina) uma das primeiras drogas experimentais aprovadas para controle da doença e buscou entrar no grupo através da médica que o diagnosticou, mas sem sucesso. Fez diversas pesquisas e descobriu que pesquisadores de outros países descobriram outras drogas que poderiam paralisar o vírus, mas que não foram aprovadas pelo governo.

Desesperado por tratamento buscou por esses medicamentos, fazendo uso de combinações de drogas licitas e ilícitas, percebendo uma significativa melhora dos sintomas, uniu forças com o jovem homossexual/travesti Rayon também soropositivo, montaram o Clube de Compras Dallas, o qual as pessoas compravam cotas e podiam receber os mesmos medicamentos usados por eles. Foram perseguidos pelo governo, mas Ron não desanimou e sempre conseguia formas de buscar as drogas.

Relacionando com o contexto social, a questão das substâncias psicoativas, principalmente as drogas consideradas ilícitas, se construiu como um problema social complexo, composto de fenômenos igualmente complexos e por agentes diversos, com posições, muitas vezes, contraditórias sobre o tema. Fatores psicossociais, culturais e ambientais apontam rupturas dos vínculos afetivos e sociais como, acondicionamento de sentimentos como a rejeição ou abandono; fuga dos problemas que não se sabe lidar (por exemplo: violência doméstica, abuso etc). Ademais, é comum que os indivíduos queiram buscar a solução de seus problemas ou o alívio para as dores da alma, no uso da droga. Geralmente não conseguem aceitar a condição humana de vida, a qual sempre terá suas frustrações e contrastes (Ramos \& Mendes, 2016; Nascimento \& Antoniassi Junior, 2016).

Retornando ao filme, a convivência com as pessoas contaminadas fez Ron Woodroof mudar seus conceitos e comportamentos, chegando a ponto de vender bens pessoais para manter aqueles que não possuíam condições financeiras de fazer o tratamento. O referido, 
contrariando as expectativas dos médicos, faleceu de Aids em 1992, sete anos depois de ser diagnosticado com o vírus.

Salienta-se que, o impacto da AIDS sobre homossexuais chegou a assumir dimensões catastróficas nos países ocidentais, já que estão entre os mais atingidos. Por outro lado, os homossexuais, sejam através de lideranças ou organizações gays, estão entre aqueles que, ainda nos anos 80 , primeiro e mais diretamente se mobilizaram para enfrentar os desafios impostos pela epidemia, não só sobre a população homossexual, como sobre outras populações específicas e sobre a população como um todo. Esta mobilização foi geradora de respostas, como a criação de diversas organizações não-governamentais de serviços em AIDS (ONGs/AIDS), produção dos primeiros manuais sobre as formas de transmissão e sobre sexo mais seguro, a promoção dos direitos humanos e da solidariedade como princípios básicos do trabalho de prevenção, entre outras (Terto Junior, 1997).

Embora estas respostas possam ter contribuído para uma tendência à estabilização no número de novos casos em alguns países, como no caso do Brasil, a associação entre AIDS e homossexualidade continua sendo motivo de debate e de análise, tanto por parte dos pesquisadores sobre sexualidade e saúde, como dos ativistas envolvidos com o enfrentamento da epidemia. No início da terceira década de convivência com a epidemia, velhos desafios se somam a novos. Entre os mais recentes, pode-se apontar a seguinte tendência: quando se aborda a saúde dos homossexuais masculinos, a primeira e imediata referência é identificar a AIDS, como se esta fosse o único problema de saúde possível nesta população, ou como se o status sorológico para o HIV fosse a única medida para avaliar a saúde de homens homossexuais (Tuller, 2001).

Tal tendência demonstra a dimensão do impacto da AIDS sobre a vida dos homossexuais e como a representação AIDS-homossexualidade ainda resiste e pode estar impondo barreiras, inclusive, às iniciativas de prevenção e assistência nessa população, assim como pode estar dificultando a compreensão de como o HIV/AIDS, assim como outros problemas de saúde, estão afetando as diferentes populações de homens que têm sexo com homens. A tendência a reduzir os problemas de saúde dos homossexuais à AIDS, podendo dificultar ainda o levantamento sobre as reais necessidades de saúde dessa população e os caminhos para adequar os serviços de saúde de forma a atender essas necessidades. Por isso, a existência é a presença do homem no mundo, senhor de sua singularidade e consciência, responsável por suas escolhas, a pessoa vivencia diversos tipos de perdas, 0 que traz um significado doloroso, coloca o homem enquanto ser vigoroso e autônomo diante de algo inevitável, faz com que ele pense a respeito de sua finitude e daqueles que ama (Guimarães \& Dias, 2017).

Rev. Psicol Saúde e Debate. Fev., 2018:4(1):161-170. 
Por fim, este filme retrata de modo fantástico o real preconceito vivido pelas pessoas soropositivas naquela época, usando a história de Ron Woodroof que antes de ser diagnosticado com o vírus, era extremamente preconceituoso, viciado em drogas, machista e que ao se ver doente e sozinho, visto que, foi abandonado pelos amigos que temiam até mesmo cumprimenta-lo por medo de serem contaminados, trava dentro de si uma luta pela sobrevivência, onde teve apoio dos homossexuais - que antes odiava -, mostrando a força que tem uma pessoa que não se entrega mesmo quando percebe que tudo está perdido, "não existe nada neste mundo que mate Ron Woodroof em trinta dias", palavras de uma pessoa desesperada, mas com uma força de vontade enorme em viver.

\section{CONSIDERAÇÕES FINAIS}

A homofobia é um tipo de discriminação injusta e estigmatizante, pois fere sistematicamente uma série de direitos básicos de cidadãos homossexuais; tais como, a moral, o livre arbítrio e a dignidade.

O século XXI caracteriza-se pela expansão das possibilidades de acesso aos meios de comunicação e a agilidade nos contatos interpessoais, quando deveríamos estar mais instruídos, mais abertos e menos ignorantes; porém o que se verifica são recorrentes conflitivas na compreensão das especificidades humanas. É assustador como cresce o número de crimes provenientes dos preconceitos e estigmas relacionados à orientação sexual das pessoas, as quais não seguem as expectativas impostas pela sociedade e tendem sofrer demasiadamente por suas identificações afetivas, como se pode verificar nos noticiários e redes sociais quase todos os dias.

Pode-se perceber que a homofobia não é um assunto remoto, o preconceito e discriminação vivida por Ron Woodroof nos anos 80 , pode ser visto com tantos outros na atualidade, apesar de muita coisa ter mudado, as pessoas estarem mais instruídas, tomando consciência que a AIDS e o uso de drogas não é exclusividade de homossexuais, que, heterossexuais e afins são tão vulneráveis quanto.

Ainda existe muito a ser estudado, verificado por diversos profissionais de psicologia, direito, profissionais da saúde, entre outros, mas precisa principalmente mudar a visão da sociedade para que todos possam viver como querem, com dignidade e tendo seus direitos constituídos como cidadão e protegidos pela lei. 


\section{REFERÊNCIAS}

Ayres, J. R. C. M (2002). Repensando conceitos e práticas em saúde pública. In: Parker, R., \& Terto, V. Jr (Org.) (2002). Aprimorando o debate: respostas sociais frente à AIDS (Anais do Seminário Prevenção à AIDS; Limites e Possibilidades na Terceira Década). Rio de Janeiro: ABIA.

Bourdieu, P (1999). A dominação masculina. Rio de Janeiro: Bertrand.

Brenner, R. et al (Produtores), \& Vallée, J. M (Diretor) (2013). Dallas Buyers Club [Filmevídeo]. Estados Unidos: Universal.

Cancian, N (2017, 19 de setembro). Justiça concede liminar que permite tratar homossexualidade como doença. Folho de São Paulo, Cotidiano, https://www1.folha.uol.com.br/cotidiano/2017/09/1919516-justica-concede-liminar-quepermite-tratar-homossexualidade-como-doenca.shtml.

Daniel, H., \& Parker, R (1991). AIDS: a terceira epidemia. São Paulo: Iglu Editora.

Exame (2011, 21 de junho). OMS: homossexuais têm 20 vezes mais probabilidades de contrair HIV. Revista Exame, Mundo, https://exame.abril.com.br/mundo/oms-homossexuaistem-20-vezes-mais-probabilidades-de-contrair-hiv/.

Guimaraes, O. O.\& Dias, C. C. A angústia de (ser) e sua interface com a existência e a morte, Psicologia Saúde em Debate, 2 (2), 42-57.

Grodira, F (2014, 01 de dezembro). Em 50 países, gays são proibidos de doar sangue por causa da AIDS. Jornal El País, Ciência, https://brasil.elpais.com/brasil/2014/11/28/ciencia/1417191728_587426.html.

Junqueira, R.D (2007). Homofobia: Limites e possibilidades de um conceito em meio a disputas. Revista Bagoas: Estudos Gays: Gêneros e Sexualidades. 1(1), 1-22.

Junqueira, R.D (2007). O Reconhecimento da Diversidade Sexual e a Problematização da Homofobia no Contexto Escolar. In: Ribeiro PRC, Silva MRS, Souza NGS, Goellner SV, Souza JF (Org.). Corpo, Gênero e Sexualidade: discutindo práticas educativas. Rio Grande do Norte: Editora da FURG.

Moreira, F.F, \& Madrid, D (2008). A HOMOSSEXUALIDADE E A SUA HISTÓRIA. Revista Etic - Encontro De Iniciação Científica, 4 (4), sp.

Nascimento, P., \& Junior, G (2016). Implicações do uso de drogas e a condição de saúde dos caminhoneiros. Psicologia e Saúde em Debate, 2 (Ed. Esp. 1), 104-116.

Oliveira, T. C. S. M (2013). Liberdade de crença religiosa e discriminação contra homossexuais. Uma análise breve sob a ótica do Projeto de Lei no 122/2006. Revista Jus Navigandi, 18 (3495), 1.

Ramos, P., \& Mende, D (2016). O olhar da psicologia sobre os motoristas usuários de substâncias psicoativas. Psicologia e Saúde em Debate, 2 (Supl. 1), 27-28 
Rios, R.R (2007). O conceito de homofobia na perspectiva dos direitos humanos e no contexto dos estudos sobre preconceito e discriminação. In: Rios RR. Em Defesa dos Direitos Sexuais. Porto Alegre: Livraria do advogado editora.

Scola, F., \& Amaral, S (2007). HOMOFOBIA. Revista Etic - Encontro De Iniciação Científica, $3(3), \mathrm{sp}$.

Silva, R., \& Bornia, J.P (2009). Homofobia: a discriminação por orientação sexual e a legislação penal brasileira. Revista Cesumar - Ciências Humanas e Sociais Aplicadas, 14 (1), 35-53.

Terto, V. Jr (1997). Reinventando a vida: histórias sobre homossexualidade e AIDS no Brasil. Tese (Doutorado em Saúde Coletiva), Universidade Estadual do Rio de Janeiro, Rio de Janeiro, RJ.

Toniette, M.A (2006). Um breve olhar histórico sobre a homossexualidade. Revista Brasileira da Sexualidade Humana, 17 (1), 41-53. 